\title{
Features of labor motivation of agro-industrial complex managers
}

\author{
Irina Abakumova ${ }^{1}$, Anna Kukulyar $^{2,}$, and Anastasia Kolenova ${ }^{1}$ \\ ${ }^{1}$ Don State Technical University, 344000, Rostov-on-Don, Russia \\ ${ }^{2}$ Southern federal university, Academy of psychology and pedagogy, 13, Nagibina ave., 344006 , \\ Rostov-on-Don, Russia
}

\begin{abstract}
In any branch of the agro-industrial complex, a special role is played by the management team. The success of an agro-industrial enterprise depends largely on the level of motivation of its head, as he forms and directs the work of subordinate personnel. Despite extensive theoretical and practical research in the field of labor motivation, these studies lack an industry-specific approach that takes into account the specifics of the labor activity of managers of the agro-industrial sector of production. The object of the study was 30 managers of various experimental production farms in the Rostov region. During the empirical study, two test methods were used: "career Anchors" (E. Shane) and "Motivational profile" (S. Ritchie and P. Martin), as well as the author's projective questionnaire. The practical significance of the work consists in scientifically-based recommendations developed based on the analysis of the results of the study. These recommendations can be taken into account by managers and employees of personnel services of enterprises in the agro-industrial area when forming systems of motivation and development of higher needs for employees who hold senior positions in modern market conditions.
\end{abstract}

\section{Introduction}

Despite extensive theoretical and practical research in the field of job motivation, these studies lack an industry-specific approach that takes into account the specifics of the work of managers in the agro-industrial sector [1-7]. Thus, the problem of the study is the need to study the features of labor motivation of managers of the agro-industrial sector in order to develop, form and introduce a new approach to labor motivation, taking into account the specifics of their personal characteristics and professional activities.

Based on this problem, we consider it appropriate to rely on the theory of motivation, consecrated by such authors as A. Maslow, K. Alderfer, D. McClelland, F. Hertzberg, V. Vroom, S. Adams, Porter, Lawler, D. McGregor, L. S. Vygodsky, A. N. Leontiev, B. F. Lomov, Ya. L.Eidelman, Yu. N. lapygin. The study of managerial aspects in motivation and stimulation of labor was considered by Shane E. H., Kibanov A. Ya., Litvak B. G., Utkin E. A., Mavlonov V. H., Chekmarev O. P., Genkin B. M., Gorshkova O. N.,

* Corresponding author: vetkina-anna@mail.ru 
Yegorshin A. P., Klochkov A. K., Israilov Sh. Sh., Klyuchevskaya I. S., Krasnopevtseva I. $\mathrm{V}$. Regarding the issues of individual motivation at the level of personality, we relied on the research of McClelland D., Martin P., Ritchie Sh., Shein E., Gerchikov V. I., Ilyin E. P., Komisarov T. A., Bondarenko I. N., Chernyshev Ya. [8-11].

\section{Discussion}

In this study, we relied on two main approaches that look at motivation from different angles: from the content and from the process. Content theories consider motivation from the point of view of the essence of its content and are based on the identification and analysis of internal human needs. The most common meaningful theories of motivation are those of A. Maslow, K. Alderfer, D. McClelland, and F. Herzberg. Procedural theories of motivation analyze a person's behavior and the process of distributing the effort needed to achieve goals. The most famous of them were the theory of expectations and preferences by V. Vroom, the theory of justice by S. Adams, the Porter-Lawler model, and the theory of "X" and "Y" by D. McGregor. These theories have made a great contribution to the practice of personnel management. A comprehensive approach to the study and practical application of the entire variety of motivational theories allows you to create effective systems of motivation and stimulation of employees.

High motivation of the staff is the most important condition for the success of any organization, including agro-industrial. Creating an effective motivation system can increase the productivity of each employee and Manager, and, as a result, the efficiency of the entire production, as well as ensure continuous growth of personnel qualifications and a favorable microclimate in the team. A complex system of motivation should include material and non-material components. The major types of motivation of work is only two: the first is through a system of external influences call for action, the internal motives of the individual to encourage him to implement actions necessary to the enterprise, the second is to form a certain motivational structure of the employee to which the job will be his an important area of life, giving inspiration and satisfaction. Sustainable motivation can be achieved by matching the needs of the employee to the rewards that they receive, since the driving force of the process of motivating work is the realization of people's needs. Creating conditions for motivation implies a maximum reduction in the number of factors that cause negative feelings in employees, and an increase in the number of positive ones. To identify the best methods of motivating staff to work, it is advisable to regularly monitor the motivators of work for rapid response to changes in the structure of motivational activity, both employees and managers of the enterprise [12-14].

Specific features of the labor activity of the head of an agro-industrial enterprise require him to have certain personal qualities, such as purposefulness, organization, enterprise and professional activity, social and professional mobility, communication and ability to cooperate, creativity, aesthetic sensitivity, special, socio-legal and autocompetence, professional self-awareness. One of the conditions necessary for the successful development of professional personal qualities of a Manager is the development of higher needs and the motivational component of the person [15].

\section{Research methods and techniques}

In the course of an empirical study on the study of the features of labor motivation of managers of the agro-industrial sector, we used the following methods: 1. "Career anchors" (E. Shane); 2. "Motivational profile" (Sh. Ritchie and P. Martin), as well as the Author's projective questionnaire. The object of the study was 30 managers who hold senior 
positions in experimental farms and settlements of the Rostov region. The entire leadership group was divided into 2 subgroups of 15 people each. As a result of the division, 1 group includes managers who have long experience of their own work in the agro-industrial sector. 2 the group is composed of senior managers. An important aspect of the selection process for respondents was their experience in the position for at least 10 years. Research hypotheses: 1. At the stage of a relatively long stay in the profession, it is possible to motivate managers of the agro-industrial complex to perform effective professional activities. 2. It is possible to develop higher needs for managers of the agro-industrial complex through a clear structuring of work and the availability of feedback, which would reduce the degree of uncertainty when performing new professional tasks.

\section{Research results}

As a result of the survey, we can conclude that the main motivating factor in both groups of managers of the agro-industrial sector is material incentives. However, in the course of their professional development, the content of the work begins to appear in the foreground: it should be interesting and bring satisfaction. And for effective work of managers within the agro-industrial sector, a clear statement of goals and objectives is necessary, as well as the presence of a friendly team and colleagues who can help the Manager to fulfill the planned plan.

As a result of the analysis of arithmetic averages of career orientations using the method of "Career anchors" by E. Shane, it was revealed that the leading career anchors for managers (group 2) are: 1 place - job stability and 2 place - service. Less pronounced career anchors: management; professional competence; entrepreneurship; integration of life styles. Almost not expressed career anchors: autonomy (independence); the challenge; the stability of the place of residence. The leading career anchors for managers with experience in the agro-industrial sector (group 1) are shown in light color: 1st place-job stability and 2nd place-service. Less pronounced career anchors: integration of life styles; autonomy (independence); professional competence; management. Virtually non-expressed career anchors: stability of residence; challenge; entrepreneurship. Both for managers (group 2) in the Figure are shown in dark color, and for managers engaged in production (group 1), the stability of the company's work is the main career orientation and the main condition that creates confidence in the future (Fig.1).

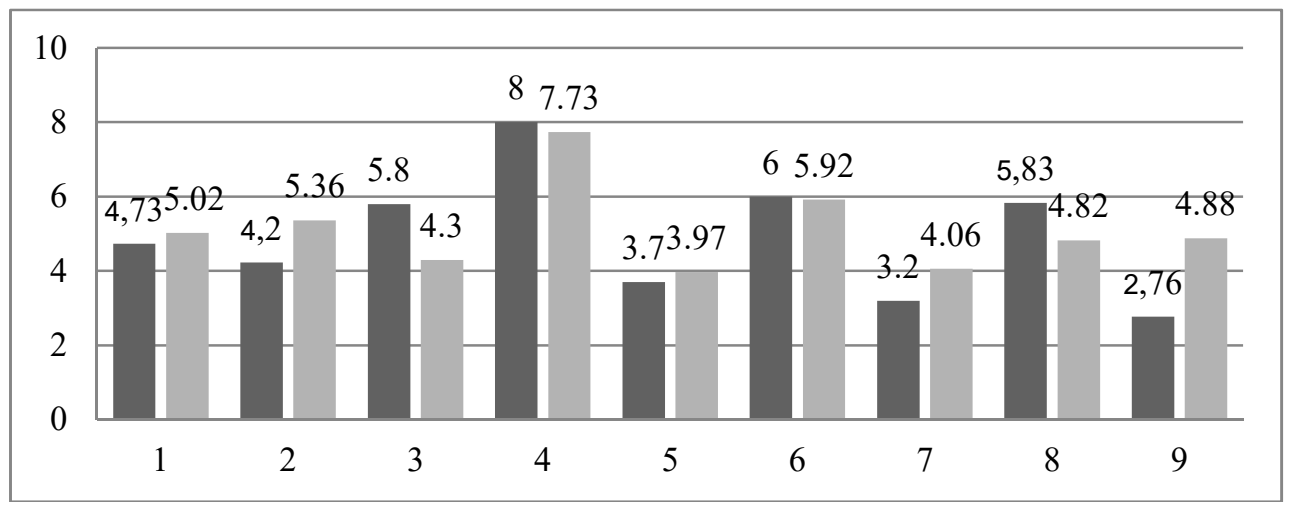

Fig. 1. Rating of "career anchors" among the entire group of managers according to the Shane method (means).

Where the vertical numerical values of indicators, and the horizontal: 1.Professional competence; 2. Management; 3. Autonomy (independence); 4. Stability of operation; 5 . The 
stability of the place of residence; 6. Service; 7. Call; 8. Integration of lifestyles; 9. Business.

As a result of the study of the motives of professional activity for the entire group of managers using the method "Motivational profile" by Sh. Ritchie and P. Martin, the following results were obtained (Fig. 2).

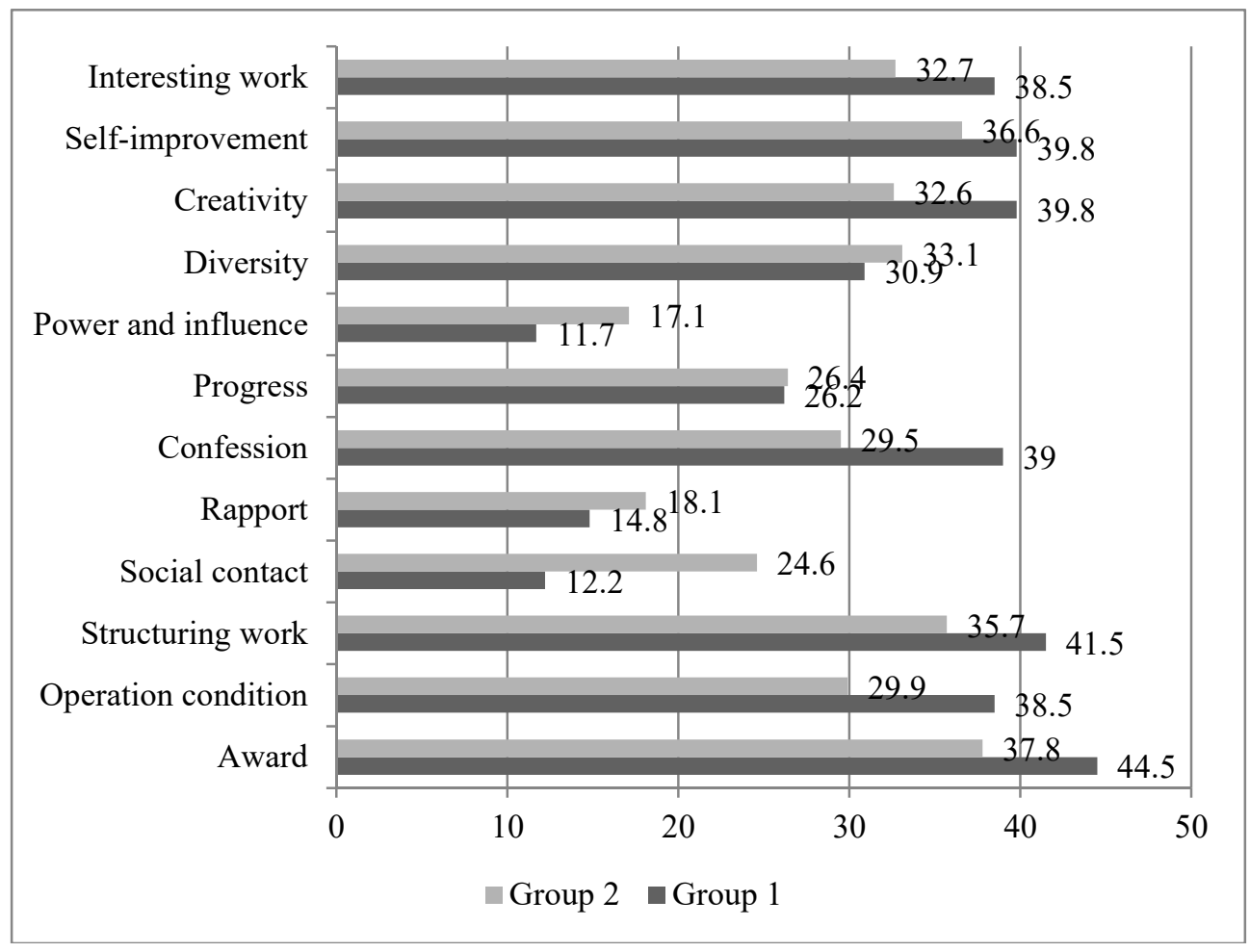

Fig. 2. Presentation of the motivational profile for 2 groups of managers according to the method by Sh. Ritchie and P. Martin.

To identify specific relationships of motivation factors, a correlation analysis was performed using the Pearson correlation coefficient. The most important thing for managers is a high salary, all sorts of benefits, incentives, and other ways of material incentives with a clear organization and structuring of work, the certainty of professional tasks and the presence of feedback from management (at $\mathrm{p}<0.05$ ). At the same time, the closeness of relationships with colleagues at work, as well as the ability to influence and lead others, does not matter to them $(a t \mathrm{p}<0.05)$. In addition, the content and variety of work, the possibility of self-improvement and creativity $($ at $\mathrm{p}<0.05)$ are of particular importance for managers and engineers.

The analysis of the motivational profile of managers with experience in the agricultural sector showed similar results. For most managers in this group, the highest value in the motivational profile was also the need for remuneration and high wages $(a t \mathrm{p}<0.05)$. The average value of this factor was 44.5. The need for well-organized and structured work, as in the previous group, came second. Factors 10 (autonomy), 11 (creativity), 12 (interesting work), 2 (good working conditions), and 6 (recognition from other people) had fairly high and approximately equal values (at $\mathrm{p}<0.05$ ). 


\section{Conclusion}

For managers, as well as for managers with experience in the agro-industrial sector, the stability of the company's work is the main career orientation and the main condition that creates confidence in the future. The focus on the stability of the place of work is peculiar to people for whom the predictability of future life events is important, due to the needs for security and stability. In addition, managers are focused on socially significant, noble motives of activity, and see in their career not only personal benefit, but also elements of benefit to society and social service.

Analysis of motivational profiles in groups of managers-managers and managers employed in production showed the dominance of external motivation, with such leading needs as remuneration and job structuring.

The predominant motivating factor in both groups of managers is defined as the need for remuneration. However, in a group of Executive managers, the need for remuneration increases when work is poorly structured and physical conditions are unfavorable, as well as when there is an opportunity to influence and control other members of the team in the process of job growth. For managers with experience in the workplace, the need for remuneration is positively correlated with the need for recognition and social contacts: the more expressed the desire for extensive contacts, gaining recognition from other people, the desire to feel their own importance, the stronger the need for material remuneration. The second predominant factor in both groups is the need to structure the work. At the same time, a clear organization of work and the presence of feedback, which would reduce the degree of uncertainty, can in turn reduce the need for material remuneration and increase the desire for creativity and self-improvement in the group of managers-managers. There are no such relationships in the group of managers who have experience in production.

Analysis of correlations of dominant motives in the group of managers showed that a clear organization of work and the presence of feedback can reduce the need for material remuneration and increase the desire for creativity and self-improvement. Analysis of correlations of dominant motives in a group of managers with experience in the workplace showed that it is possible to reduce the need for material remuneration by meeting the needs for recognition and social contacts: such a Manager must be given the opportunity to win recognition from other people, have extensive social contacts, and feel their own importance. The need for interesting and useful work for society is at a very low level in both study groups. However, in a group of Executive managers, the interest in work is closely linked to its creative component, which allows for creativity and the possibility of self-improvement. In the group of managers who have experience in production, the relationship between these factors is already absent. The desire for creativity and selfimprovement is closely linked by all managers to the need to set complex goals and achieve them. Therefore, in order to develop the creative component of work for managers, it is necessary to develop simultaneously the desire for achievements.

Thus, the hypothesis 1 that at the stage of a relatively long stay in the profession, motivation for effective professional activity for managers of the agro-industrial complex is possible was fully confirmed. Hypothesis 2 that it is possible to develop higher needs for managers of the agro-industrial complex through a clear structuring of work and the presence of feedback that would reduce the degree of uncertainty in the performance of new professional tasks has been fully confirmed.

\section{References}

1. J.W. Atkinson, Motives in fantasy, action, and society (Van Nostrand, Princeton, NJ, 2017) 
2. J.F. Brennan, History and systems of psychology (Prentice-Hall, Inc. Englewood Cliffs, NJ, 2012)

3. L.T. Benjamin, ISIS 98(4), 842-843 (2017)

4. C.S. Carver, M. F. Scheier, Perspectives on personality, 7th edition (Allin And Bacon, 2013)

5. Fr. Herzberg, B. Mausner, B. Bloch Snyderman, The motivation to work (Transaction Piscataway, New Jersey, 2017)

6. T.H. Leahy, History of modern psychology (Prentice Hall, Englewood Cliffs, New Jersey, 2011)

7. H. Petrie, J. Govern, Motivation: theory, research, and applications (6th ed.) (2013)

8. K. Sheldon, Modern trends in motivation and emotions (2010)

9. D.C. McClelland, D.H. Burnham, Power is a great motivator (Harvard Business School Press, Boston, 2018)

10. D.C. McClelland, J.W. Atkinson, R.A. Clark, E.L. Lowell, The motive of achievement (Van Nostrand, Princeton, NJ, 2013)

11. T.F. Pettijohn, Psychology: a ConnecText (McGraw-hill, 2018)

12. W.E. Pickren, A. Rutherford, A history of modern psychology in context (John Wiley \& Sons, Inc., Hoboken, New Jersey, 2010)

13. B. Souders, 20 most popular theories of motivation in psychology https://positivepsychology.com/motivation-theories-psychology/ 